\title{
Profile and spatial distribution on maternal mortality
}

Carla Alaíde Machado Ruas 1

(D) https://orcid.org/0000-0002-8039-311X

Joice Fernanda Costa Quadros 2

iD https://orcid.org/0000-0002-7753-951X

Jucimere Fagundes Durães Rocha 3

https://orcid.org/0000-0003-0150-4932

Fernanda Cardoso Rocha 4

https://orcid.org/0000-0001-6381-2063

Gregório Ribeiro de Andrade Neto 5

https://orcid.org/0000-0002-1417-5237

\author{
Álvaro Parrela Piris 6 \\ (iD) https://orcid.org/0000-0002-7151-5015 \\ Bruna Roberta Meira Rios 7 \\ (iD) https://orcid.org/0000-0002-7715-2921 \\ Sabrina Gonçalves Silva Pereira 8 \\ https://orcid.org/0000-0001-8737-6569 \\ Claudia Danyella Alves Leão Ribeiro 9 \\ (iD) https://orcid.org/0000-0002-5063-3733 \\ Giselle Mara Mendes Silva Leão 10 \\ iD https://orcid.org/0000-0002-2475-4208
}

\footnotetext{
1,2,4,9 Centro de Ciências Biológicas e da Saúde. Universidade Estadual de Montes Claros. Av. Dr. Ruy Braga, s.n. Vila Mauriceia. Montes Claros, MG, Brasil. CEP: 39.401089. E-mail: nandac.rocha@hotmail.com

3,5,10 Faculdades de Saúde e Humanidades Ibituruna. Ibituruna. Montes Claros, MG, Brasil.

6-8 Instituto de Ciências da Saúde. Montes Claros, MG, Brasil.
}

\begin{abstract}
Objectives: to describe profile and spatial distribution on maternal mortality in a city in the North of Minas Gerais-Brazil.

Methods: a descriptive, cross-sectional, documentary and quantitative study was carried out in 31 (100\%) Fichas de Investigação de Óbito Materno do Comitê de Mortalidade Materna (Maternal Mortality Investigation Data Forms from the Maternal Mortality Committee) from 2009 to 2013.

Results: prevalence is observed in women between 20 and 34 years old, mixed race, single and with low schooling. Of the deaths classified, $48.2 \%$ are direct obstetric death and $74.2 \%$ would be likely avoidable. The most prevalent causes of death were pregnancy-specific hypertensive disease; circulatory system disease; neoplasms; coagulopathies and post-abortion infection. In relation to prenatal care, only 20 women performed it, and most performed less than six prenatal consultations and in relation to the end of gestation, $68.1 \%$ underwent cesarean childbirth. Regarding to the descriptive spatial analysis, we identified a higher occurrence of maternal deaths in the areas of medium and high social vulnerability.

Conclusions: maternal mortality is a strong indicator of women's healthcare, there is a necessity to readjust women's healthcare in the puerperal pregnancy cycle. New healthcare practices for women are needed, due to the referred bond and responsible care.
\end{abstract}

Key words Maternal and child health, Mortality records, Maternal mortality

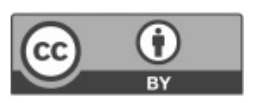




\section{Introduction}

Maternal Mortality (MM) is a severe public health problem, especially in developing countries, where $99 \%$ of maternal deaths occur. ${ }^{1}$ Its decrease is one of the Millennium Development Goals, whose objective was to reduce the Maternal Mortality Ratio (MMR) by three quarters by the end of 2015.2

The World Health Organization (WHO) describes that pregnancy, childbirth and postpartum complications kill more than half a million women a year worldwide, and about another 10 million who are left with sequelae suffer during the puerperal pregnancy cycle. 1 Despite this situation, there are signs of improvement; studies indicate that there are more women of reproductive age with access to care by the health team in Brazil, resulting in the best care, consequently reducing complications. ${ }^{3}$

Analyzing the MMR trend in Brazil, estimates from the Secretaria de Vigilancia em Saúde (SVS) (Health Surveillance Secretary) of the Ministério da Saúde (MS) (Ministry of Health) showed a reduction of 52\% in MMR, declining from 143 deaths per 100 thousand Live Births (LB) in 1990, to 68 per 100 thousand LB in 2010. However, the rate of reduction of the MMR has decreased since 2001, revealing the need for greater efforts to achieve lower values of LB deaths. ${ }^{4}$

In Brazil, in the period of 2009 to 2013, there was a significant decrease in maternal mortality in 2009 to $20.04 \%$, in 2011 it was $20.07 \%$ and in 2013 the maternal deaths was $19.93 \% .4$

More than half of maternal and neonatal deaths occur during the woman's hospitalization for childbirth and birth; around $15 \%$ of the deaths are due to unsafe abortion; $51 \%$ of the neonatal deaths occur in the first week of life and are mostly related to problems arising from childbirth; about $70 \%$ of women's deaths occur from direct obstetric causes. 5

It is noteworthy mentioning the MM concept which in turn is defined as woman's death during pregnancy or within a period of 42 days after the termination of pregnancy, independently of the duration or the pregnant woman's location due to any cause related or aggravated by the pregnancy and its managing, but not by accidental or incidental causes. ${ }^{5}$ In general, the MM expression suggests that death occurs prematurely, with preventable causes, reflecting not only the lives of these women, but also the level of organization and the quality of care it is provided. 6

The high degree of avoidability of MM shows deficiencies in healthcare services, which can be aggravated by unfavorable socioeconomic conditions. Complications related to the puerperal preg- nancy cycle are among the main preventable causes of death in women of reproductive age, giving several global initiatives to intensify interventions aimed in reducing them. ${ }^{7}$

With the creation of the various Comitês de Mortalidade Materna (Maternal Mortality Committees) in Brazil, there was an improvement of maternal death underreporting registrations in the interpretation of these indexes over the years and so, deaths have become more rigorously notified, mitigating the real reduction in maternal mortality ratio, compared to nowadays. ${ }^{6}$ In Brazil, the high inconsistencies in the MMR values suggest low effectiveness of public policies to address this issue. The improvement of reproductive health conditions is a challenge, since risk situations affect mainly women with little access to health services. This fact requires quality prenatal and childbirth care, effective social control with expansion and qualification of the Comitês de Morte Materna (Maternal Death Committees) and mobilization of managers, health professionals and civil society in promoting public policies that seek to reduce maternal mortality. 8

MM remains a major challenge for managers and society in developing countries. Despite the complexity of its determinants, maternal death is socially unacceptable, as it is recognized as a protective role in care received by women during the entire gestational process. 9

This present study has a general objective, to describe the profile and spatial distribution on maternal mortality in a city in the North of Minas Gerais, Brazil, from 2009 to 2013. It is believed that the knowledge on profile and spacial distribution of this mortality needs to be expanded, to better understand the causes that lead to women's death in order to produce and disseminate information that can support the plan of action and public policies that seek to reduce maternal mortality in the studied scenario.

\section{Methods}

The research was submitted to the Research Ethics Committee (CEP) of the Universidade Estadual de Montes Claros (Unimontes) and was approved through Consubstantiated Document No. 984,824 on March 13, 2015.

This is a descriptive, cross-sectional, documentary and quantitative study, carried out in the city of Montes Claros, located in the North of Minas Gerais State. The data source was from the Programa Saúde da Mulher (Woman's Health Program), specifically from the Comitê Municipal de Mortalidade Materna 
(Municipal Maternal Mortality Committee) sector. The use of the data began in May 2015, in 31 (100\%) of the Fichas de Investigação de óbito Materno (Maternal Death Investigation Forms) M1, M2, M3, M4 and M5 of the Comitê Mortalidade Materna (Maternal Mortality Committee) in the period of 2009 to 2013; after the approval by the Research Ethics Committee (CEP). It was also necessary to collect secondary data on the number of live births in the period of 2009 to 2013 in DATASUS 4 to calculate the Razão de Mortalidade Materna (Maternal Mortality Ratio) in the city. This calculation takes into account the number of women's deaths according to causes and conditions considered maternal death (direct and indirect), divided by the number of live births and after multiplying by $100,000.4$

The Fichas de Investigação (Investigation Forms) M1, M2, M3, M4 and M5 are applied to all deaths in Mulher em Idades Fértil (MIF) (Women in Fertile Ages), between 10 and 49 years old, the forms were multiple choice and open questions. The forms have general and common information such as: woman's identification, place and city where the death occurred and maternal death identification. There were also specific items detailing the investigation of each level of care provided, which will be described below:

- Ficha de Investigação de Óbito Materno (Maternal Death Investigation Form) M1: includes data referring to Serviço de Saúde Hospitalar (Outpatient Health Service), there are information on prenatal care and data on women's care in public or private hospital services and urgent / emergency services.

- Ficha de Investigação de Óbito Materno (Maternal Death Investigation Form) M2: addresses information from the Hospital Health Service, collects data regarding the woman's hospitalization during the illness that led to death, childbirth or abortion care, in addition to contemplating data on the newborn.

- Ficha de Investigação de Óbito Materno (Maternal Death Investigation Form) M3: refers to home interview, allows to collect information about the woman and the family's characteristics and life conditions, healthcare provided for the woman during her pregnancy and the criticism on the services.

- Ficha de Investigação de Óbito Materno (Maternal Death Investigation Form) M4: this is the Ficha de Coleta de Dados de Laudo de Necrópsia (Necropsy Data Collection Report Form) that details the maternal death and allows the data transition from the autopsy report and the records are available on the body's referrals at the morgue.

- Ficha de Investigação de Óbito Materno (Maternal Death Investigation Form) M5: this is a synthesis, conclusions and recommendations covering the most relevant aspects and registers the analysis of the investigated case. 10

To guide the data collection, a spreadsheet containing the following variables was used: sociodemographic profile - age, marital status, race/color, place of residence, schooling, how many people live at home and private health insurance; epidemiology profile- risk factors during pregnancy, use of medication during pregnancy, if the pregnancy was of risk when the patient died and gave birth up to twelve months before her death, was maternal death disregarded and what was the moment of this disregard; reproductive (or obstetric) profile: number of pregnancies, type of chilbirth, whether it resulted in abortion, what type of death after the abortion, type of delivery in case of death during childbirth or puerperium and place of delivery or abortion; care profile - prenatal care, type of service where the prenatal care was performed, date of the first consultation, gestational age of the first consultation, gestational age of the last consultation and number of prenatal visits.

After the collection, the data were submitted to simple descriptive analysis in absolute numbers and percentages. The SPSS software version 2.0 and spatial analysis R software version 3.1 were used.

For spatial analysis, 216 census tracts were considered as study analysis units according to data from the Pesquisa Nacional de Amostragem por Domicilio (PNAD) (National Research of Household Sampling) in 2010 in the city of Montes Claros. ${ }^{11}$ The digital base of the census tracts used for this study was generated by $\mathrm{R}$ software version 2.15 .

It is important to highlight that the spatial analysis on maternal deaths in this study was performed by analyzing only 22 maternal deaths out of the 31 total cases, as nine cases did not have complete address information that allow to locate for spatial analysis. The spatial analysis aimed to perform a geoprocessing of cases of maternal deaths in absolute numbers according to the census tracts and according to social vulnerability in the city.

For spatial analysis with a social vulnerability indicator was decided to adopt the Índice de Vulnerabilidade Social - 5 (IVS-5) (Social Vulnerability Index-5) and validated in Rio Grande do Sul. 12 The purpose of creating the IVS-5 was to validate a social vulnerability indicator made up of few items, obtained from public databases and that 
represented the relation between health and society. The IVS-5 uses six items indicating poverty and difficulty in the provision of services, which are selected from the Censo do IBGE (IBGE Census) in 2010 , to constitute indicators of social vulnerability, namely: percentage of households with monthly income per capita up to half the minimum wage; percentage of households not connected to the water distribution network; percentage of households without garbage collection; percentage of households without bathrooms or toilets connected to the general sewage or rain network; percentage of illiteracy among people over 15 years of age; demographic density.

For the IVS-5 classification of the census tracts in the city of Montes Claros, the PNAD database (2010) was used.11 After submitting these data to statistical treatments as directed by Drachler et al.,12 to generate the IVS-5 in the city of Montes Claros, was created a social vulnerability as an indicator whose values ranged from -0.25 to 1 , with the highest value attributed to the most vulnerable census tracts and the lowest value, to at least vulnerable reaching the following result of IVS-5 stratification for Montes Claros, with results of: below 0.25 with low social vulnerability; those between 0.25 to zero (0), average social vulnerability; those above zero (0) with high social vulnerability.

\section{Results}

In Table 1 as presented, the data on mortality women of childbearing age, maternal death, considering women's death during pregnancy and / or within 42 days of pregnancy termination, the Razão de Mortalidade Materna (Maternal Mortality Ratio) are distributed in absolute numbers, and the distribution of maternal deaths according to classification, and according to year of occurrence in the city of Montes Claros-MG in the period of 2009 to 2013.

As also shown in Table 1, the highest rates of maternal deaths are linked to the direct obstetric causes, registering at $48.4 \%$ in the studied group. Regarding to the classification according to avoidability, we can observe that the classification of preventable deaths is $74.4 \%$. The study also reveals high rates of undeclared deaths at $29.2 \%$, a classification that is taken under consideration when the registered information does not allow to classify death as maternal.

In Table 2 shows the sociodemographic characteristics of maternal deaths distributed in absolute number and percentage in the city of Montes ClarosMG from 2009 to 2013, whereas, most women were between 20 and 34 years old (61.3\%), 70.9\% selfdeclared being mixed, $32.2 \%$ had incomplete elementary schooling and $45.2 \%$ were single.

In Table 3 shows data relating to women's prenatal care, whereas, the majority $(64.5 \%)$ performed prenatal care and these 20 women who had follow-ups, most (80.0\%) performed prenatal care at the Primary Health Care unit (PHC). More than half of the women $(65 \%)$ began late prenatal care after the second trimester; $60 \%$ had up to six prenatal consultations and $58.1 \%$ were classified as high risk pregnancies, but only $45.2 \%$ received prenatal care for high risk pregnancy and $38.7 \%$ were hospitalized during pregnancy.

As for the variables related to childbirth and postpartum care shown in Table 4, most of those who progressed to termination of pregnancy had a cesarean section $(68.1 \%)$; the procedure was performed at a maternity hospital $(81.8 \%)$; in relation to complications, the most frequent one was bleeding (33.4\%); and the majority $(72.7 \%)$ had no complications in the postpartum period.

In Table 4 still presents data on the characteristics of maternal deaths from 2009 to 2013, with a distribution in absolute number and percentage. Most deaths occurred in the hospital (87.1\%); the main cause of death was Sindrome Hipertensiva da Gestação-DHEG (Gestational Hypertension Syndrome) and neoplasms (19.4\%) and the study points out that the majority of the failures were in care $(41.9 \%)$.

The spatial information analyzed the construction of overlapping thematic maps of social vulnerability and maternal deaths (Figure 1) presenting the spatial distribution of cases on maternal deaths in absolute numbers in census tracts in Monte ClarosMG in the period of 2009 to 2013. Each dark spot on the map represents the occurrence of a case on maternal death. Although, the immediate visual impact, reproduces the heterogen distribution and presents the determined spatial occupation by geographical, social and economic aspects.

This same figure shows the spacial distribution of the social vulnerability in this same city, according to census tracts calculated through the IVS-5, which the areas in light gray (120 (55.5\%) census tracts) have the IVS-5 below -0.25 are considered as areas of low social vulnerability, and the areas with a medium gray shade (67 (31\%) census tracts) have the IVS- 5 between -0.25 to zero (0) being considered areas of medium social vulnerability and the areas with dark gray coloring (29 $(13.5 \%)$ census tracts) have the IVS-5 above zero (0) being considered areas of high social vulnerability. 
Distribution in absolute number of deaths of women of childbearing age, live births, MMR and the distribution of these maternal deaths, according to classification in the city of Montes Claros-MG in the period of 2009 to 2013.

\begin{tabular}{lcccc}
\hline Year & $\begin{array}{c}\text { Deaths of women } \\
\text { in age fertile }\end{array}$ & Maternal deaths & Live Births & MMR \\
\hline 2009 & 126 & 4 & 5,770 & 69.32 \\
2010 & 119 & 7 & 5,831 & 120.04 \\
2011 & 119 & 3 & 5,637 & 53.21 \\
2012 & 135 & 9 & 5,765 & 156.11 \\
2013 & 117 & 8 & 5,860 & 136.51 \\
Total & 616 & 31 & 28,863 & 535.19
\end{tabular}

$\begin{array}{lll}\text { Final classification } & & 48.4 \\ \text { Direct obstetric maternal death } & 15 & 25.8 \\ \text { Indirect obstetric maternal death } & 08 & 12.9 \\ \text { Late obstetric maternal death } & 04 & 3.2 \\ \text { Inconclusive } & 01 & 9.7 \\ \text { Non-obstetric } & 03 & 74.2 \\ \text { Second avoidability of death } & & 25.8 \\ \text { Probably avoidable } & 23 & 70.8 \\ \text { Probably inevitable } & 08 & 29.2 \\ \text { Second Declaration } & & 100.0 \\ \text { Declared Maternal Deaths } & & 22 \\ \text { Undeclared Maternal Deaths } & 09 & \\ \text { Total } & & 31\end{array}$

Source: Database of the City Maternal Mortality Investigation Committee of the City Health Department of Montes Claros, Minas Gerais, Brazil, 2015. MMR= Maternal Mortality Ratio.

\section{Discussion}

The study shows that the year with the highest number of maternal deaths was the highest MMR in 2012, with 9 deaths from 5,675 LB with MMR of 138.76 per 100,000 LB in the city of Montes Claros - MG. However, it is observed that in the five years studied, the rates are high when compared to the recommended value by the WHO, which is 20 per 100,000 LB. 13 The WHO estimated that in 2010 there were 287,000 maternal deaths, MMR of 210 for every $100,000 \mathrm{LB}$ in the world, which is considered as ideal was 10 deaths per 100,000 LB, and the acceptable was up to 20 deaths per 100,000 LB. 6,11

Although, Brazil is making progress in reducing mortality, it has not reached the millennium goal, whose objective would be an MMR equal to or less than 35 deaths per 100 thousand LB. In the country, the MMR projection varied from 69 to 77 deaths per 100 thousand LB between 2008 to 2015.11 More recent data show that in Brazil, 1,670 maternal deaths occurred in 2016, which ranks outside the established goal. 14

As for the socio-demographic profile and the classifications of maternal deaths according to causes and avoidability, this study showed results similar to other studies regarding age, 15 race, $, 9,16$ schooling, 9 marital status, $7,9,16$ in direct obstetric maternal death 6,9 and preventable deaths. 6,16

It is a fact that maternal mortality has a close relation with discrimination and with Brazilian women's biological and socio-cultural determinants, especially with inequalities of gender, low schooling 
Table 2

Distribution in $\mathrm{N}$ and percentage (\%) of the sociodemographic variables on maternal deaths in the city of Montes Claros - MG in the period of 2009 to 2013.

\begin{tabular}{|c|c|c|}
\hline Variables & $\mathbf{N}$ & $\%$ \\
\hline \multicolumn{3}{|l|}{ Age (years) } \\
\hline$\leq 19$ & 03 & 9.7 \\
\hline $20-34$ & 19 & 61.3 \\
\hline$\geq 35$ & 09 & 29.0 \\
\hline \multicolumn{3}{|l|}{ Race/Color } \\
\hline White & 03 & 9.7 \\
\hline Black & 03 & 9.7 \\
\hline Yellow & - & - \\
\hline Mixed & 22 & 70.9 \\
\hline Indigenous & - & - \\
\hline Not informed & 03 & 9.7 \\
\hline \multicolumn{3}{|l|}{ Schooling } \\
\hline Incomplete Elementary School & 10 & 32.2 \\
\hline Complete Elementary School & 02 & 6.4 \\
\hline Incomplete high school & 04 & 12.9 \\
\hline Complete high school & 09 & 29.2 \\
\hline Incomplete Higher Education & 02 & 6.4 \\
\hline Not informed & 04 & 12.9 \\
\hline \multicolumn{3}{|l|}{ Martial Status } \\
\hline Single & 14 & 45.2 \\
\hline Married & 08 & 25.8 \\
\hline Stable union & 07 & 22.6 \\
\hline Not informed & 02 & 06.4 \\
\hline Total & 31 & 100.0 \\
\hline
\end{tabular}

Source: Database of the City Maternal Mortality Investigation Committee of the City Health Department of Montes Claros, Minas Gerais, Brazil, 2015.

Table 3

Distribution in absolute number and percentage (\%) of data related to prenatal care on maternal deaths in the city of Montes Claros - MG in the period of 2009 to 2013.

\begin{tabular}{lcc}
\hline Variable & N & $\%$ \\
\hline Prenatal care & & 64.5 \\
Yes & 20 & 35.5 \\
No & 11 & 100.0 \\
Total & 31 & 80.0 \\
Place that performed prenatal care & 16 & 5.0 \\
UAPS-SUS & 01 & 15.0 \\
High Risk Referred Center - SUS & 03 & 100.0 \\
Private office & 20 &
\end{tabular}

continue

Source: Database of the City Maternal Mortality Investigation Committee of the City Secretary of Health of Montes Claros, Minas Gerais, Brazil, 2015. 
Distribution in absolute number and percentage (\%) of data related to prenatal care on maternal deaths in the city of Montes Claros - MG in the period of 2009 to 2013.

\begin{tabular}{|c|c|c|}
\hline Variable & $\mathbf{N}$ & $\%$ \\
\hline \multicolumn{3}{|l|}{ First prenatal consultation } \\
\hline First quarter & 04 & 20.0 \\
\hline Second quarter & 10 & 50.0 \\
\hline Third quarter & 03 & 15.0 \\
\hline No registration & 03 & 15.0 \\
\hline Total & 20 & 100.0 \\
\hline \multicolumn{3}{|l|}{ Number of prenatal consultations } \\
\hline From 1 to 3 prenatal consultations & 03 & 15.0 \\
\hline From 3 to 6 prenatal consultations & 09 & 45.0 \\
\hline More than 6 prenatal consultations & 05 & 25.0 \\
\hline No registration & 03 & 15.0 \\
\hline Total & 20 & 100.0 \\
\hline \multicolumn{3}{|l|}{ Risk rating } \\
\hline Usual risk & 06 & 19.4 \\
\hline High risk & 18 & 58.1 \\
\hline No registration & 07 & 22.5 \\
\hline Total & 21 & 100.0 \\
\hline \multicolumn{3}{|l|}{ High risk care } \\
\hline Yes & 14 & 45.2 \\
\hline No & 17 & 54.8 \\
\hline Total & 31 & 100.0 \\
\hline \multicolumn{3}{|l|}{ Hospitalization during pregnancy } \\
\hline Yes & 12 & 38.7 \\
\hline No & 19 & 61.3 \\
\hline Total & 31 & 100.0 \\
\hline
\end{tabular}

Source: Database of the City Maternal Mortality Investigation Committee of the City Secretary of Health of Montes Claros, Minas Gerais, Brazil, 2015.

Table 4

Distribution in absolute number and percentage (\%) of variables related to childbirth and postpartum on maternal deaths and the characteristics of these maternal deaths in the city of Montes Claros-MG in the period of 2009 to 2013.

\begin{tabular}{llc}
\hline Variable & N & \% \\
\hline Termination of pregnancy & & 70.9 \\
Childbirth & 22 & 16.2 \\
Abortion & 05 & 12.9 \\
Without Childbirth & 04 & 100.0 \\
Total & 31 & 27.3 \\
Type of delivery & & 4.6 \\
Vaginal & 06 & 68.1 \\
Forceps & 01 & 100.0 \\
Cesarean & 15 & 22 \\
Total & & \\
\hline
\end{tabular}

Source: Database of the City Maternal Mortality Investigation Committee of the City Secretary of Health of Montes Claros, Minas Gerais, Brazil, 2015.

continue 
Distribution in absolute number and percentage (\%) of variables related to childbirth and postpartum on maternal deaths and the characteristics of these maternal deaths in the city of Montes Claros-MG in the period of 2009 to 2013.

\begin{tabular}{|c|c|c|}
\hline Variable & $\mathbf{N}$ & $\%$ \\
\hline \multicolumn{3}{|l|}{ Place of childbirth } \\
\hline Maternity & 18 & 81.8 \\
\hline Residence & 03 & 13.6 \\
\hline Others & 01 & 4.6 \\
\hline Total & 22 & 100.0 \\
\hline \multicolumn{3}{|c|}{ Types of complications at childbirth } \\
\hline Fetal suffering & 01 & 16.7 \\
\hline Pre eclampsia & 01 & 16.7 \\
\hline Hypertonia & 01 & 16.7 \\
\hline Bleeding & 02 & 33.2 \\
\hline Others & 01 & 16.7 \\
\hline Total & 06 & 100.0 \\
\hline \multicolumn{3}{|l|}{ Postpartum complications } \\
\hline Without complications & 16 & 72.7 \\
\hline With complications & 06 & 27.3 \\
\hline Total & 22 & 100.0 \\
\hline \multicolumn{3}{|l|}{ Postpartum complications } \\
\hline Bleeding & 01 & 16.7 \\
\hline Placenta acreta & 01 & 16.7 \\
\hline Uterine atony & 02 & 33.2 \\
\hline Others & 02 & 33.2 \\
\hline Total & 06 & 100.0 \\
\hline \multicolumn{3}{|l|}{ Place of death } \\
\hline Hospital & 27 & 87.1 \\
\hline Residence & 01 & 3.2 \\
\hline Midwife House & 01 & 3.2 \\
\hline No registration & 02 & 6.5 \\
\hline Total & 31 & 100.0 \\
\hline \multicolumn{3}{|l|}{ Cause of death } \\
\hline Hellp syndrome & 01 & 3.2 \\
\hline Post-abortion infection & 05 & 16.1 \\
\hline DHEG & 06 & 19.4 \\
\hline Infectious diseases & 01 & 3.2 \\
\hline Neoplasms & 06 & 19.4 \\
\hline External causes & 04 & 12.9 \\
\hline Neurological disease & 02 & 6.5 \\
\hline Circulatory system disease & 03 & 9.7 \\
\hline Uterine atony & 01 & 3.2 \\
\hline Coagulopathies & 01 & 3.2 \\
\hline Undetermined causes & 01 & 3.2 \\
\hline Total & 31 & 100.0 \\
\hline \multicolumn{3}{|l|}{ Location of failure } \\
\hline Access & 06 & 19.4 \\
\hline Care & 13 & 41.9 \\
\hline Access and Care & 12 & 38.7 \\
\hline Total & 31 & 100.0 \\
\hline
\end{tabular}

Source: Database of the City Maternal Mortality Investigation Committee of the City Secretary of Health of Montes Claros, Minas Gerais, Brazil, 2015. DHEG = sindrome hipertensiva da gestação (Gestational Hypertension Syndrome). 


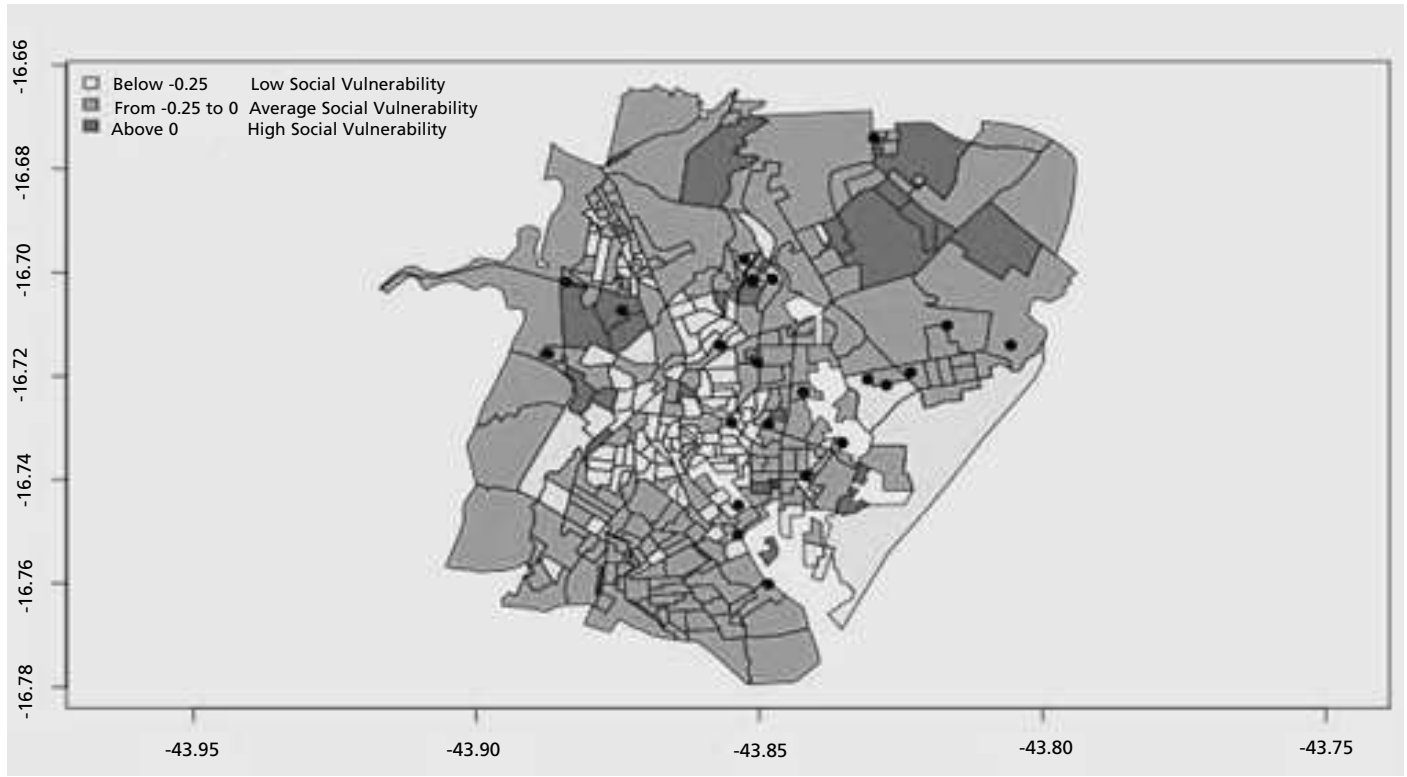

Source: Database of the City Maternal Mortality Investigation Committee of the City Health Secretary of Montes Claros, Minas Gerais, Brazil, 2015 and PNAD, IBGE; 2010.

and race. It is also noteworthy that the quality of care interferes directly with this issue. 3

In this investigation, there was a predominance of women's deaths between the age group of 20 to 34 years old, mixed race, single and low schooling, the results are similar in a study 7 from the Universidade Federal de Minas Gerais (Federal University of Minas Gerais) in 2013 in which 61.5\% of the women were between 20 and 34 years old, $48.3 \%$ were mixed race, $60.3 \%$ were single and $29.7 \%$ had less than seven years of schooling. This observed trend of data published in Brazil can be verified in population-based studies developed in different regions of the country, such as found in the city of Montes Claros. ${ }^{17,18}$

Regarding to maternal age at the time of death, there is a predominance of age between 20 and 34 years old, a fact that can be justified, since it is the range that concentrates the highest reproductive activity, 17,18 with similar data being identified in one study, such as the one from the Universidade Federal de Minas Gerais, which has a rate of 52.5\% of maternal deaths in this same age group. ${ }^{7}$

As for race, dark-skinned women have a higher genetic predisposition to diseases, especially hypertensive syndromes in pregnancy (HSP), and it must be considered that their exposure to greater social vulnerability conditions makes their access difficult in receiving better quality in the health services. 16,19

In relation to schooling, the lower the women's schooling level the higher the risk of maternal mortality, and the limited access to education can have negative consequences, ranging from poor understanding on specific recommendations during pregnancy even having difficulties in accessing services due to the disability in recognizing a risky situation. 20,21

The data regarding the classification of maternal deaths presented in the present study show that almost half $(48.4 \%)$ were due to direct obstetric, which theoretically would be preventable deaths, and the average in the literature according to Brazilian contexts, is higher, around $67 \% .6$ In a study conducted at a referral center in the Southeast of Brazil that analyzed cases on maternal deaths from 1999 to 2010 , observed that $44.9 \%$ of the causes are also direct obstetric death that this may be associated with care deficiencies in conducting the 
cases, with a possible reversal, if the women had been properly assisted at the ideal time. 15

In regards to avoidability, the data show high rates $(74.2 \%)$, among the analyzed deaths, the same way that the literature shows when there is a predominance of direct obstetric causes. In a study conducted in the Southeast of Brazil, it verifies that $35.2 \%$ of the deaths could be avoided. These facts relate to care failures already addressed as delays in care, ranging from the delay in demanding for service, the delay in the secondary service in recognizing the severity of the case and leading the highrisk cases to an ideal service, which in most severe situations can be decisive for the outcome. 6,15

As for prenatal care, the researched population here, only 20 women underwent prenatal, the most of them (60\%) performed less than six (6) prenatal consultations which is the minimum consultations recommended. Prenatal comprises a set of procedures which aims to prevent, diagnose and treat undesirable events in the pregnancy, at childbirth and the newborn, the which can contribute to a better care. Their absence and/or disability is related to higher rates of maternal and perinatal morbidity and mortality. Studies indicate that pregnant women who attend prenatal care services and have adequate care, have fewer complications and their fetuses show adequate intrauterine growth, demonstrating the relation between prenatal care and the newborn and mother's well-being. 22

Even at birth, which usually occurs at the hospital the inadequacy of prenatal care carries a higher risk for adverse pregnancy outcomes. 23 In a study in Rio de Janeiro, which evaluated maternal deaths with the persistence of severity were considered preventable, despite the increased coverage of prenatal care and the number of consultations offered in recent years, maternal mortality still has high values, close to 50 per 100 thousand LB, suggesting in reflecting the quality of the service provided. The causes of the vast majority of deaths could be avoided through prenatal care with adequate and quality in guidance, identifying possible complications during pregnancy and intervening to avoid further complications for the pregnant woman. 22

In relation to the type of childbirth, the research shows that $68.1 \%$ underwent cesarean delivery, this fact has had a direct impact on maternal and early neonatal mortality and on the increasing rates of prematurity and low birth weight. The Brazilian Public Health System (SUS) registers an increase in its percentage of cesarean surgeries, from $37.8 \%$ in 2000 to $46.5 \%$ in 2009 . This high rate, which reaches $90 \%$ in the supplementary health sector, has provided our country the title of world champion in performing elective cesarean sections, as well as contributing to the increase in the percentage of births of babies with low weight and major complications for maternal health. 5

Although, cesarean section has been recognized as a surgical procedure to save and preserve the mother and newborn's health, cesarean deliveries increase the risk of maternal and perinatal morbidity and mortality, especially in situations where medical indications are not accurate. Several studies suggest the risk of complications such as post cesaren is much greater than that associated with vaginal delivery, whereas, the rates are between $16 \%$ and $27 \%$ on post cesarean complications, among them have been described as: haemorrhage, wound infection and hematoma, infection urinary tract, endometritis and puerperal fever, although more frequent in intrapartum cesarean sections, compared to those electively decided.24

The Ministry of Health in 2009 analyzed the health situation in Brazil highlighting that more than half of maternal deaths occurred during woman's hospitalization for childbirth and the birth; about $70 \%$ of maternal deaths occurred from direct obstetric causes; approximately of $15 \%$ of deaths were caused by unsafe abortion; relating to mainly with problems arose from childbirth. 5 In a survey conducted in the State of Paraíba, it was observed that direct obstetric deaths, mainly related to hypertensive syndromes were responsible for approximately one quarter of maternal deaths in Brazil, which indicated problems in the quality of care or lack of prenatal care. 19

Regarding to the causes of death, the research highlights the specific hypertensive diseases in pregnancy and neoplasms, which had a higher rate of $19.4 \%$. These causes are also observed in other studies, as in the city of Belo Horizonte in 2013, which the most frequent causes of MM were infectious, hypertensive and hemorrhagic, with a considerable number of clinical-surgical causes and neoplasms as causes of death. 6

$\mathrm{MM}$ is always a challenging topic, due to its impact on society, its possible avoidability, or even the difficulty in reducing its occurrence worldwide. Despite the numerous strategies used, it remains a difficult problem to solve, which makes it unlikely that the United Nations' Millennium Development Goals will be achieved by reducing maternal mortality by $75 \%$ from 1990 to $2015.6,15$ Also we should keep in mind that the risk of a woman dying during pregnancy or childbirth is about one in five 
of the poorest regions in the world, compared to the rate about one of 30,000 in the North of Europe.6,17 This factor is also important to reflect on the global commitment in reducing maternal mortality.

In this perspective, it is observed that many women do not know or assert their rights, submitting themselves to the system and to the health professional, especially in moments surrounded by fears and weaknesses, such as pregnancy, childbirth and the postpartum period. Poor social control, biomedical conceptions, the culture on pregnancy as a disease and childbirth as a dangerous event, the lack of autonomy and disbelief in the physiology and power of the female body, cause women to be restricted in their citizenship, which makes it difficult to process the necessary evolution and social change. 3

Regarding the descriptive spatial analysis, although not very high, identifies a higher occurrence on maternal deaths in the areas of medium and high social vulnerability. This result contradicts the findings of the evaluation study on Maternal Mortality Ratio and social exclusion conducted by Zacarias 25 in São Paulo, from 2000 to 2008, indicating the need for further studies, trying to see whether there is a correlation between social vulnerability and maternal mortality. This finding also suggests to reflect on the interface among living conditions, poverty and health. This theme is already recurrent in contemporary studies that attempt to incorporate new analytical frameworks and interdisciplinary approaches for conceptual thought and methodology on poverty, social inequality and health, taking into account that the confrontation of the phenomenon requires policies that go beyond the sectoral cutout and seek integrated actions with the greatest potential in alterating the vulnerability of the framework.

In the results obtained there is a predominance of deaths in women between the age group of 20 to 34 years old, mixed race, single and with low schooling. Regarding the classification of maternal deaths, $45 \%$ were direct obstetric death and $80.6 \%$ were likely to be preventable, the most prevalent causes of death were: pregnancy-specific hypertensive disease; circulatory system disease; neoplasms; coagulopathies and post-abortion infection.

It cannot be ignored that maternal mortality is a strong indicator on women's health care, the findings of this investigation point to the need in readjusting healthcare for women in the postpartum pregnancy cycle. There is a need for new healthcare practices for women, which must be referred in the bond and accountability of obstetric care in situations such as high-risk pregnancies. Qualified care respecting women's citizenship rights and humanization of care with an early capture of pregnant women at prenatal care, referral to high-risk prenatal care, enhancement on women's complaints and active search, in cases where pregnant woman for some reason interrupted the care, care in the puerperium are important factors for the avoidability of maternal deaths. Therefore, the expansion of access to health services and the effective commitment of medical professionals and nurses involved in assisting the mother during prenatal care, childbirth and also in the puerperium, is of paramount importance.

It is also believed that further studies on descriptive spatial analysis of maternal mortality may support the organization and plan of actions and strategies in the area of sexual and reproductive health for women of reproductive age in the city of Montes Claros, as one of the advantages of using IVS-5 with spatial analysis is that spatial mapping on social risk that clearly indicates the territories of greatest risk in the city, enabling to plan more specific actions directed for these areas in a context of health surveillance of care units where planning and action is the territory and has its multiple cuts.

\section{Authors' contributions}

Ruas CAM, Quadros JFC contributed in the concept of the article design and data collection, Rocha JFD, participated in the data analysis, correction, revision and general guidance. Rocha FC, Andrade Neto GR contributed to the design, revision and standardization. Piris AP, Rios BRM, Pereira SGS, Ribeiro CDAL and Leão GMMS contributed to the correction and critical review of the article. All authors approved the final version of the manuscript and are publicly responsible for the content of the article. 


\section{References}

1. WHO (World Health Organization). Trends in Maternal Mortality1990 to 2008. Geneva; 2010. Disponível em: http://apps.who.int/iris/bitstream/10665/44874/1/97892415 03631_eng.pdf.

2. Hogan MC, Foreman KJ, Naghavi M, Ahn SY, Wang M, Makela SM, Murray CJ. Maternal mortality for 181 countries, 1980-2008: a systematic analysis of progress towards Millennium Development Goal 5. Lancet. 2010; 375 (9726): 1609-23

3. Narchi NZ, Cruz EF, Gonçalves R. O papel das obstetrizes e enfermeiras obstetras na promoção da maternidade segura no Brasil. Ciênc Saúde Coletiva. 2012; 105 (4): 1059-68.

4. Brasil. Ministério da Saúde. Secretaria de Vigilância em Saúde. Indicadores e Dados Básicos. Diário Oficial União. Brasília, DF; 2011. Disponível em http://tabnet.datasus.gov.br/cgi/idb2011/C03b.htm

5. Brasil. Ministério da Saúde. Uma análise da situação de saúde e da agenda nacional e internacional de prioridades em saúde. Diário Oficial União. Brasília, DF; 2010. Disponível: http://bvsms.saude.gov.br/bvs/publicacoes/ saude_brasil_2009.pdf

6. Troncon JK, Quadros ND, Leonel RPM, Cecatti JG, Surita FG. Mortalidade materna em um centro de referência do Sudeste Brasileiro. Rev Bras Ginecol Obst. 2013; 35 (9): 388-94. Disponível em: http://www.scielo.br/scielo.php? pid $=$ S0100-72032013000900002\&script $=$ sci_arttext

7. Resende LV. O Contexto e perfis característicos da mortalidade materna em Belo Horizonte (MG), 2003-2010. Belo Horizonte, 2013. [Tese]. Belo Horizonte: Faculdade de Ciências Econômicas da Universidade Federal de Minas Gerais; 2013. Disponível em: http://www.bibliotecadigital.ufmg.br/dspace/bitstream/handle/1843/AMSA$986 \mathrm{~N} 8 \mathrm{G} /$ tese lilianresende.pdf?sequence $=1$

8. Morse ML, Fonseca SC, Barbosa MD, Calil MB, Eyer FPC Mortalidade materna no Brasil: o que mostra a produção científica nos últimos 30 anos. Cad Saúde Pública. 2011; 2 (4): 623-38

9. Borges CLMS, Costa MCN, Mota ELA. Evolução temporal e diferenciais intra-urbanos da Mortalidade Materna em Aracaju, Sergipe, 2000-2010. Epidemiol Serv Saúde. 2013; 22 (2): 307-16

10. Brasil. Ministério da Saúde. Manual dos Comitês de Mortalidade Materna/Ministério da Saúde. Secretaria de Políticas de Saúde, Área Técnica de Saúde da Mulher. 2 ed. Diário Oficial União. Brasília, DF; 2002. Disponível em: http://bvsms.saude.gov.br/bvs/publicacoes/manual comites mortalidade materna.pdf

11. IBGE (Instituto Brasileiro de Geografia e Estatística) Pesquisa Nacional por Amostra de Domicílios - Síntese de Indicadores 2009. Rio de Janeiro: IBGE. 2010. Disponível em: https://biblioteca.ibge.gov.br/visualizacao/livros/ liv45767.pdf

Received on April 9, 2018

Final version presented on October 10, 2019

Approved on December 20, 2019
12. Drachler ML, Lobato MADO, Lermen JI, Fagundes S, Ferla AA, Drachler CW, Leite J. CDC. Desenvolvimento e validação de um índice de vulnerabilidade social aplicado a políticas públicas do SUS. Ciênc Saúde Coletiva. 2014; 19 (9): 3849-58.

13. OMS (Organização Mundial da Saúde). Cid-10: classificação estatística internacional de doenças e problemas relacionados à saúde. São Paulo: Edusp; 1997.

14. TabNet Win32 3.0: Óbitos de mulheres em idade fértil e óbitos maternos - Brasil. Disponível em: http://tabnet.datasus.gov.br/cgi/tabcgi.exe?sim/cnv/mat10uf .def

15. Oliveira NAF, Parpinelli MA, Cecatti JG, Souza JP, Sousa MH. Factors associated with maternal death in women admitted to an intensive care unit with severe maternal morbidity. Int J Gynaecol Obstet. 2009; 105 (3): 252-6.

16. Teixeira NZ, Pereira WR, Barbosa DA, Vianna LAC. Mortalidade materna e sua interface com a raça em Mato Grosso. Rev Bras Saúde Matern Infant. 2012; 12 (1): 2735 .

17. Souza ML, Laurenti R, Knobel R, Monticelli M, Brüggemannet OM, Drake E. Mortalidade materna por hemorragia no Brasil. Rev Latino-am Enferm. 2013; 21 (3): 27-35.

18. Soares VMN, de Souza, KV, Freygang TC, Correa V, Saito MR. Mortalidade materna por pré-eclâmpsia/eclâmpsia em um estado do Sul do Brasil Maternal mortality due to preeclampsia/eclampsia in a state in Southern Brazil. Rev Bras Ginecol Obstetr. 2009; 31 (11): 566-73.

19. Marinho ACDN, Paes NA. Maternal mortality in the state of Paraíba-Brazil: association between variables. Rev Esc Enferm USP. 2010; 44 (3): 732-8.

20. Leite RMB, Araújo TVBD, Albuquerque RMD, Andrade ARSD, Duarte Neto PJ. Fatores de risco para mortalidade materna em área urbana do Nordeste do Brasil. Cad Saúde Pública. 2011; 27(10): 1977-85.

21. Correia RA, Araújo HC, Furtado BMA, Bonfim C. Características epidemiológicas dos óbitos maternos ocorridos em Recife, PE, Brasil (2000-2006). Rev Bras Enferm. 2011; 64 (1): 91-7.

22. Domingues RMSM, Hartz ZMA, Dias MAB, Leal MC. Avaliação da adequação da assistência pré-natal na rede SUS do Município do Rio de Janeiro, Brasil. Cad Saúde Pública. 2012; 28 (3): 425-37.

23. Silva AMR, Almeida MF, Matsuo T, Soares DA. Fatores de risco para nascimentos pré-termo em Londrina, Paraná, Brasil. Cad Saúde Pública. 2009; 25 (21): 25-38.

24. Freitas PF, Savi EP. Desigualdades sociais nas complicações da cesariana: uma análise hierarquizada. Cad Saúde Pública. 2011; 27 (10): 2009-2020.

25. Zacarias TSF. Mortalidade materna no município de São Paulo, 2000-2008. [Tese]. São Paulo: Faculdade de Saúde Pública da Universidade de São Paulo; 2013. Disponível em: http://www.teses.usp.br/teses/disponiveis/6/6132/tde12042013-103426/en.php 